\title{
NeuroD1 Regulates Expression of Thyroid Hormone Receptor $\beta 2$ and Cone Opsins in the Developing Mouse Retina
}

\author{
Hong Liu, ${ }^{1}$ Paige Etter, ${ }^{2}$ Susan Hayes, ${ }^{2}$ Iwan Jones, ${ }^{3}$ Branden Nelson, ${ }^{2}$ Byron Hartman, ${ }^{2}$ Douglas Forrest, ${ }^{1}$ and \\ Thomas A. $\operatorname{Reh}^{2}$ \\ ${ }^{1}$ Clinical Endocrinology Branch, National Institute of Diabetes and Digestive and Kidney Diseases-National Institutes of Health, Bethesda, Maryland 20892, \\ ${ }^{2}$ Department of Biological Structure, University of Washington, Seattle, Washington 98195-7420, and ${ }^{3}$ Department of Human Genetics, Mount Sinai School \\ of Medicine, New York, New York 10029
}

The correct patterning of opsin expression in cone photoreceptors is critical for normal color vision. Thyroid hormone, and one of its receptors [thyroid hormone receptor $\beta 2$ (TR $\beta 2$ )], is an important regulator of opsin expression during cone photoreceptor development. Mice have two genes, encoding medium-wavelength (M) and short-wavelength (S) cone opsins. Targeted deletion of TR $\beta 2$ leads to a uniform expression of S-opsin in all cone photoreceptors and a loss of M-opsin. The control of expression of TR $\beta 2$ is therefore central to cone differentiation, yet there is little known about its regulation in the retina. We now report that the proneural bHLH (basic helix-loophelix) transcription factor, NeuroD1, is necessary for sustained expression of TR $\beta 2$ in immature cone photoreceptors. Mice deficient in NeuroD1 develop an opsin phenotype virtually identical with that of TR $\beta 2$-deficient mice: all cones express S-opsin, and none expresses M-opsin. The introduction of NeuroD1 into embryonic retinal explants from NeuroD1 ${ }^{-1-}$ mice restores TR $\beta 2$ expression. NeuroD1 binds an E-box in the intron control region of the TR $\beta 2$ gene that mediates cone-specific expression, suggesting that NeuroD1 is a critical contributory factor to the expression of $\mathrm{TR} \beta 2$ in cones. These results thus connect the proneural pathway with opsin selection to ensure correct cone patterning during retinal development.

Key words: TR $\beta 2$; S-opsin; M-opsin; proneural; bHLH; photoreceptor

\section{Introduction}

The expression of the various opsin genes by subpopulations of cone photoreceptors underlies color vision. The molecular pathways regulating the expression of a specific opsin gene in the different subpopulations of photoreceptors are beginning to be elucidated. We previously showed that one of the thyroid hormone receptors, thyroid hormone receptor $\beta 2$ (TR $\beta 2)$, and its heterodimer partner, retinoid X receptor $\gamma(\mathrm{RXR} \gamma)$, are critical regulators of this process in mice (Ng et al., 2001; Roberts et al., 2005). Mice deficient in TR $\beta 2$ lack medium-wavelength (M)opsin, and all cones instead express short-wavelength (S)-opsin (and the S-opsin expression begins several days prematurely). Mice deficient in RXR $\gamma$ also have premature S-opsin expression in all cones, although their M-opsin expression is normal (Roberts et al., 2005). We also found that these developmental deci-

Received Oct. 24, 2007; revised Nov. 25, 2007; accepted Nov. 30, 2007.

This work was supported in part by National Institutes of Health (NIH) Grant NS28308 (T.A.R.) and Grant DC03441 (D.F.), The Hirschl Trust, and the Intramural Program at the National Institute of Diabetes and Digestive and Kidney Diseases-NIH (D.F.). We thank Dr. Ming-Jer Tsai (Baylor College of Medicine, Houston, TX) for providing the mice with a targeted deletion of NeuroD1. We also thank Dr. Amy Weinman for help with the ChIP analysis. Thanks to Dr. Olivia Bermingham-McDonogh for critical comments throughout the course of these studies.

Correspondence should be addressed to Dr. Thomas A. Reh, Department of Biological Structure, University of Washington, Box 357420, Seattle, WA 98195. E-mail: tomreh@u.washington.edu.

DOI:10.1523/JNEUROSCI.4832-07.2008

Copyright $\odot 2008$ Society for Neuroscience $\quad$ 0270-6474/08/280749-08\$15.00/0 sions regulating cone opsin expression require the ligand for TR $\beta 2$ (Roberts et al., 2006).

The regulation of TR $\beta 2$ in developing cones is therefore critical for their development. The factors that control the conespecific expression of TR $\beta 2$ are not known. Several transcription factors are known to be expressed in developing cones before the onset of TR $\beta 2$, including Otx2 (Nishida et al., 2003), Crx (Furukawa et al., 1997), and $\mathrm{Rb}$ (Zhang et al., 2004). In addition, several members of the basic helix-loop-helix (bHLH) class of transcription factors are expressed in developing photoreceptors, including Math3 and NeuroD1 (Ahmad et al., 1998; Yan and Wang, 1998, 2000, 2004; Morrow et al., 1999; Pennesi et al., 2003). Recent analysis of the Thrb gene that encodes TR $\beta 2$ (Jones et al., 2007) identified a cone-specific, intronic control region. This control region contains an E-box consensus site for a bHLH class transcription factor, suggesting that a bHLH factor expressed in the developing cones might be a regulator of $\operatorname{TR} \beta 2$ expression.

We examined the expression of cone opsin genes and TR $\beta 2$ in mice deficient for NeuroD1 and found a cone opsin phenotype identical with that of the TR $\beta 2$-deficient mouse retina: all the cones express S-opsin, whereas M-opsin expression is almost undetectable. Moreover, TR $\beta 2$ is markedly reduced in expression levels. NeuroD1 binds to and activates the cone-specific control element of the TR $\beta 2$ gene in a cell-specific manner. This analysis 
reveals that NeuroD1 plays an important role in cone photoreceptor development and suggests that it does so by contributing to the developmental induction of $\operatorname{TR} \beta 2$, a key factor in determining opsin patterning.

\section{Materials and Methods}

Oligonucleotides. Oligonucleotides used in the study are listed in supplemental Table 1 (available at www.jneurosci.org as supplemental material).

Animals. BETA2/NeuroD1-null mice were generated in the 129SvJ background as described previously (Liu et al., 2000a,b). NeuroD1 ${ }^{-/-}$ and wild-type (wt) mice were genotyped using three primers to detect wild-type and mutant alleles. Reactions containing all three primers were amplified for 34 cycles $\left(1 \mathrm{~min}\right.$ at $34^{\circ} \mathrm{C}, 1 \mathrm{~min}$ at $56^{\circ} \mathrm{C}, 1 \mathrm{~min}$ at $\left.72^{\circ} \mathrm{C}\right)$. All experiments were conducted in accordance with the guidelines of the University of Washington Institutional Animal Care and Use Committee.

Tissue preparation. For immunofluorescence labeling, retinas were dissected in cold PBS, fixed for $2 \mathrm{~h}$ in $4 \%$ paraformaldehyde, rinsed in PBS, and equilibrated in $30 \%$ sucrose $/ \mathrm{PBS}$ overnight at $4^{\circ} \mathrm{C}$. Retinas were frozen (OCT, Tissue-Tek; Sakura Finetek, Torrance, CA) and cryosectioned at $12 \mu \mathrm{m}$. Sections were incubated overnight with primary antibodies [1:500 rabbit M-opsin, 1:500 rabbit S-opsin (both from Jack Saari, University of Washington, Seattle, WA), 1:200 rabbit S-opsin (AB5407; Chemicon International, Temecula, CA), 1:5000 rabbit TR $\beta 2$ (13), or goat NeuroD1 N-19 (SC-1084; Santa Cruz Biotechnology, Santa Cruz, $\mathrm{CA})$ ] and for $2 \mathrm{~h}$ in secondary antibodies (1:500 Alexa Fluor goat antirabbit 568, donkey anti-goat 488, or donkey anti-rabbit 594; Invitrogen, Carlsbad, CA). Cone outer segments were visualized with FITCconjugated peanut lectin (L7381; Sigma-Aldrich, St. Louis, MO). Slides were viewed on a fluorescent or confocal microscope and photographed with a digital camera.

For flat-mount studies, retinas were flattened on a glass slide, fixed with $4 \%$ paraformaldehyde for $15 \mathrm{~min}$, and fixed for an additional hour in a 24-well plate. Retinas were incubated in primary antibodies at the concentrations noted previously for $48 \mathrm{~h}$ at $4^{\circ} \mathrm{C}$ and in secondary antibodies overnight at $4^{\circ} \mathrm{C}$. To label all cones, we incubated retinas in FITCconjugated peanut lectin for $48 \mathrm{~h}$ at $4^{\circ} \mathrm{C}$. Retinas were mounted in 1:1 glycerol/water between coverslips separated with an imaging Chamber (Secure-Seal; Grace Bio-Laboratories, Bend, OR). Flat mounts were viewed on a confocal microscope.

Retinal explant culture. Embryonic day 14 (E14) NeuroD1 mice were harvested and genotyped. Electroporation was used to transfect retinal explants with a mixture of NeuroD1 and E12 expression plasmids in pCS2 + (gifts from E. Turner, University of California, San Diego, San Diego, CA), and CAGGs-green fluorescent protein (GFP) (chick $\beta$-actin promoter). Briefly, retinas were submerged in a Millicell culture-plate insert (Millipore, Bedford, MA) filled with $\mathrm{HBSS}+$, and positioned over an underlying electrode (positive). DNA solution was applied to the apical surface and the negative electrode was positioned over the explant. Electroporation conditions were as follows: five pulses, $35 \mathrm{~V}, 50 \mathrm{~ms}$ pulse length, $100 \mathrm{~ms}$ pulse interval (BTX T820). Retinas were allowed to recover, and then transferred to new Millicell inserts, and cultured as flattened explants for $4 \mathrm{~d}$ as described previously (Nelson et al., 2007). Retinas were fixed in $4 \%$ paraformaldehyde and immunolabeled as whole mounts for GFP and TR $\beta 2$ expression as above.

Quantitative PCR. Levels of S-opsin, M-opsin, TR $\beta 2$, Crx, rhodopsin, and NeuroD1 mRNA were measured by quantitative PCR, using cDNA prepared from wild-type and NeuroD1-null retinas as described previously (Kubota et al., 2004). We analyzed two to four individuals of each genotype and age. Primer sequences are available on request.

Chromatin immunoprecipitation assay. Chromatin immunoprecipitation (ChIP) was performed as described by Weinmann et al. (2001) with minor modifications. For ChIP analysis of Weri and 293T cells, the cells were cross-linked in $1 \%$ formaldehyde in $1 \times$ PBS at room temperature for $10 \mathrm{~min}$ before adding $1 \mathrm{~m}$ glycine to stop the reaction. The lysis was performed by six cycles of $20 \mathrm{~s}$ sonication and $40 \mathrm{~s}$ pause on ice, using a Sonic Dismembrane model 500 (Fisher Scientific, Houston, TX) at 30\% output. The ChIP procedure followed standard instructions from Upstate Biologicals (Lake Placid, NY). The immunoprecipitated DNA was analyzed by real-time PCR with SYBR Green PCR master mix kit (Applied Biosystems, Foster City, CA) with probes for four different regions of the Thrb gene.

Plasmids. A $1.2 \mathrm{~kb}$ NeuroD1 cDNA was isolated from mouse brain mRNA by reverse transcription (RT)-PCR based on sequences under accession no. NM_010894, and cloned into pSG5. The TR $\beta 2$ promoter ( -570 to first exon ATG) and intron region $(730 \mathrm{bp})$ were cloned into a luciferase reporter, the promoterless pREP4 episomal vector (Liu et al., 2001). Deletions and mutations were introduced into the intron fragment by PCR-mediated mutagenesis or QuikChange Site-Directed Mutagenesis (Stratagene, La Jolla, CA) and checked by DNA sequencing.

Transfection, luciferase, and small interfering RNA assays. Weri cells and HEK293T cells were grown as described previously (Jones et al., 2007). 293T cells were transfected with $10 \mu \mathrm{g}$ of pSG5-NeuroD1 plasmid using Superfect reagent (Qiagen, Hilden, Germany), and nuclear extracts were collected after $48 \mathrm{~h}$. Weri cells were transfected with $200 \mathrm{ng}$ of pREP4 reporter vectors, 10 ng of pSV-RL Renilla internal control plasmid and pSG5 empty carrier DNA using Fugene HD reagent (Roche, Indianapolis, IN). After $60 \mathrm{~h}$, cells were lysed and luciferase activity was assayed with the dual-luciferase system with normalization to Renilla activity (Promega, Madison, WI). The small interfering RNA (si-RNA) expression system was used to knock-down endogenous NeuroD1 protein level in Weri cells and the result on expression of a cotransfected luciferase reporter. Four different fragments targeted against NeuroD1 were inserted into pSilencer-4.1 CMV plasmid (Ambion, Austin, TX) (see supplemental material, available at www.jneurosci.org). The pSilencer4.1-negative control plasmid (Ambion) expressed a nonspecific sequence. The activity of the si-RNA vectors was first established in 293T cells cotransfected with NeuroD1 expression plasmid (see supplemental material, available at www.jneurosci.org). Weri cells were transfected with $200 \mathrm{ng}$ of pREP4 reporter vector, $10 \mathrm{ng}$ of pSV-RL Renilla plasmid, and $1.2 \mu \mathrm{g}$ of si-RNA control (pSilencer4.1 plasmid) or anti-NeuroD1 si-RNA plasmids (a mix of all four) using Fugene HD reagent (Roche). Transfected cells were selected under $450 \mu \mathrm{g} / \mathrm{ml}$ neomycin for $80 \mathrm{~h}$, before harvesting and assay of luciferase activity.

Electrophoretic mobility shift assay and Western blots. Electrophoretic mobility shift assay (EMSA) was performed with $2 \mu \mathrm{g}$ of nuclear protein and $2 \mathrm{~nm}$ labeled probe as described previously (Srinivas et al., 2006). Probes were labeled by biotin $3^{\prime}$-end labeling and bands were detected with a Lightshift Chemiluminescent EMSA kit (Pierce, Rockford, IL). Antibody against NeuroD1 ( $3 \mu \mathrm{l}$, affinity-purified; Santa Cruz) was preincubated with nuclear extract at $4^{\circ} \mathrm{C}$ for $1 \mathrm{~h}$ before the addition of probe, and then further incubation at room temperature for $15 \mathrm{~min}$ to demonstrate band specificity. Competition was performed against 2 nм labeled probe using excess unlabeled wt or mutant probe. Sequences for probes are given in supplemental Table 1 (available at www.jneurosci.org as supplemental material) (E600, M600, control secretin gene probe) $(\mathrm{Mu}-$ toh et al., 1997). For Western blots, primary antibodies were as follows: Flag (Abcam, Cambridge, MA; 1:1000), b-actin (Chemicon; 1:1000), and NeuroD1 (Santa Cruz; 1:100). Secondary antibodies used were HRPgoat anti-mouse $\operatorname{IgG}(\mathrm{H}+\mathrm{L})$ and HRP-rabbit anti-goat $\operatorname{IgG}(\mathrm{H}+\mathrm{L})$ (Zymed, San Francisco, CA) (1:3000 dilution).

\section{Results}

NeuroD1 is expressed in the developing and mature retina in both photoreceptors and amacrine cells in frog, chick, and mammals (Kanekar et al., 1997; Ahmad et al., 1998; Yan and Wang, 1998; Morrow et al., 1999; Pennesi et al., 2003). In other regions of the CNS, although primarily expressed in postmitotic cells, NeuroD1 has also been found in some mitotically active progenitor cells (Lee et al., 2000). To determine whether NeuroD1 is expressed in mitotically active progenitor cells in the mouse retina, we injected pregnant mice with 5-bromo-2' ${ }^{\prime}$-deoxyuridine (BrdU) to label the S-phase cells, killed the animals $2 \mathrm{~h}$ later, and then processed the tissue for in situ hybridization and immunofluorescence. Figure 1 shows a section through an E14.5 mouse 

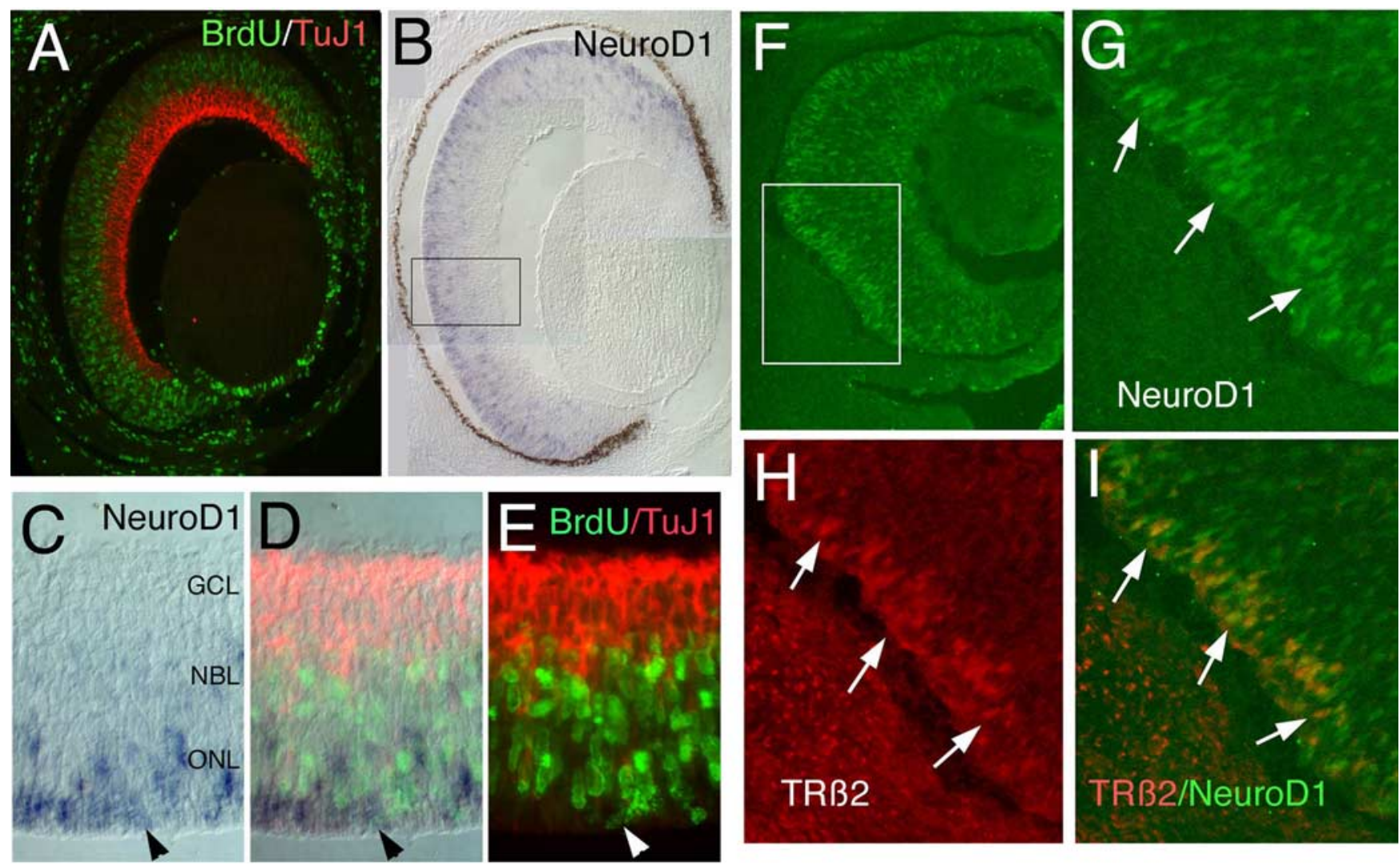

Figure 1. $\boldsymbol{A}-\boldsymbol{E}, \mathrm{E} 14.5$ mouse retina, after in situ hybridization for NeuroD1 (purple; $\boldsymbol{B}-\boldsymbol{D}$ ), and immunofluorescent labeling for BrdU (green; $\boldsymbol{A}, \boldsymbol{D}, \boldsymbol{E}$ ) and Tuj1 (red; $\boldsymbol{A}, \boldsymbol{D}, \boldsymbol{E}$ ). Only an occasional cell double-labeled for both BrdU and NeuroD1 (arrow) can be found. $\boldsymbol{F}$-I, Double-labeling with antibodies to NeuroD1 (green) and TR $\beta 2$ (red) shows that nearly all TR $\beta 2$-labeled cells also express NeuroD1 (arrows), although many NeuroD1-expressing cells do not express TR $\beta 2$. GCL, Ganglion cell layer; NBL, neuroblastic layer.

retina, labeled for NeuroD1, BrdU, and Tuj1, to label the amacrine cells and ganglion cells. The NeuroD1-expressing cells are found primarily on the scleral surface, in the developing outer nuclear layer $(\mathrm{ONL})$. Most of the NeuroD1-expressing cells are not labeled for BrdU, but we find an occasional cell doublelabeled for both BrdU and NeuroD1 (arrow). TR $\beta 2$ is expressed by cone photoreceptors as early as E13.5 (Roberts et al., 2005, 2006). To determine whether NeuroD1 is expressed in developing cone photoreceptors, we labeled E15 mouse retina with antibodies to both NeuroD1 and TR $\beta 2$ (Fig. $1 F-I$ ). Most, if not all, of the TR $\beta 2$-labeled cells coexpress NeuroD1, although many NeuroD1-expressing cells do not express TR $\beta 2$ and are likely to be developing rod photoreceptors or amacrine cells (Morrow et al., 1999; Pennesi et al., 2003). Thus, NeuroD1 is expressed in postmitotic cone photoreceptors.

To determine whether NeuroD1 is necessary for cone photoreceptor development, we analyzed retinas from NeuroD1 ${ }^{-1-}$ mice at postnatal days 12-16 for expression of cone-specific opsins. We chose to analyze the mice at this age, because most of the NeuroD $1^{-/-}$mice do not live to adulthood, and those that do have severe neurological defects and diabetes (Pennesi et al., 2003). In addition, NeuroD $1^{-/-}$mice have a slow retinal degeneration, such that by 2 months of age, the photoreceptor cell number is reduced by $20-30 \%$ (Pennesi et al., 2003), thus complicating analyses at older ages. Figure 2 shows the retinas of wild-type and NeuroD1 ${ }^{-/-}$littermates labeled for either S-opsin or M-opsin and peanut lectin agglutinin (PNA) to label the total cone population. Wild-type animals have a distinct gradient in opsin expression, with M-opsin predominant in cones in the dorsal retina and S-opsin predominant in the ventral retina. In contrast, NeuroD1 ${ }^{-1-}$ mouse retinas have only S-opsinexpressing cones; there is little to no $\mathrm{M}$-opsin expression. The overall cone numbers, assessed by PNA staining, are not significantly different between the wild type and the mutant [wt, $387 \pm$ $43 / 0.5 \mathrm{~mm}^{2}(n=5)$; het, $498 \pm 47 / 0.5 \mathrm{~mm}^{2}(n=4)$; ko, $591 \pm$ $98 / 0.5 \mathrm{~mm}^{2}(n=3) ; n=$ number of mice of each genotype from two separate litters], indicating that the loss of M-opsin expression is not attributable to a selective degeneration of M-opsinexpressing cones. Analysis of retinal sections from NeuroD $1^{-/-}$ mice also confirmed the data from the flat-mounted retinas (supplemental Fig. 1, available at www.jneurosci.org as supplemental material). Quantitative RT-PCR confirmed that M-opsin expression is $\sim 10$-fold lower in the mutant retinas, compared with the wild type, whereas S-opsin is not significantly different.

The loss of M-opsin and the uniform S-opsin expression in cone photoreceptors is similar to the phenotype in TR $\beta 2^{-1-}$ mice (Ng et al., 2001). We therefore used quantitative RT-PCR to test whether TR $\beta 2$ expression was altered in the NeuroD1 ${ }^{-l-}$ retinas and found $\mathrm{a} \sim 10$-fold reduction in the TR $\beta 2 \mathrm{mRNA}$ levels at postnatal day 12 (Fig. 2 I). Our previous studies have shown that $\mathrm{TR} \beta 2$ is required to prevent premature $\mathrm{S}$-opsin expression (Ng et al., 2001). If NeuroD1 regulates TR $\beta 2$ expression, we reasoned that loss of NeuroD1 might also lead to premature S-opsin expression. Using immunofluorescence, we found that, at early stages of development, TR $\beta 2$ is initially expressed in NeuroD $1^{-1-}$ mice, but it is quickly and prematurely downregulated, such that by E16, NeuroD1 ${ }^{-1-}$ mice have threefold less TR $\beta 2$ than normal, as detected by RT-PCR (Fig. 3A). At E17, TR $\beta 2$ labeling is markedly reduced in the developing cones (Fig. $3 B, C$ ). In contrast, we find premature expression of S-opsin in the Neu- 

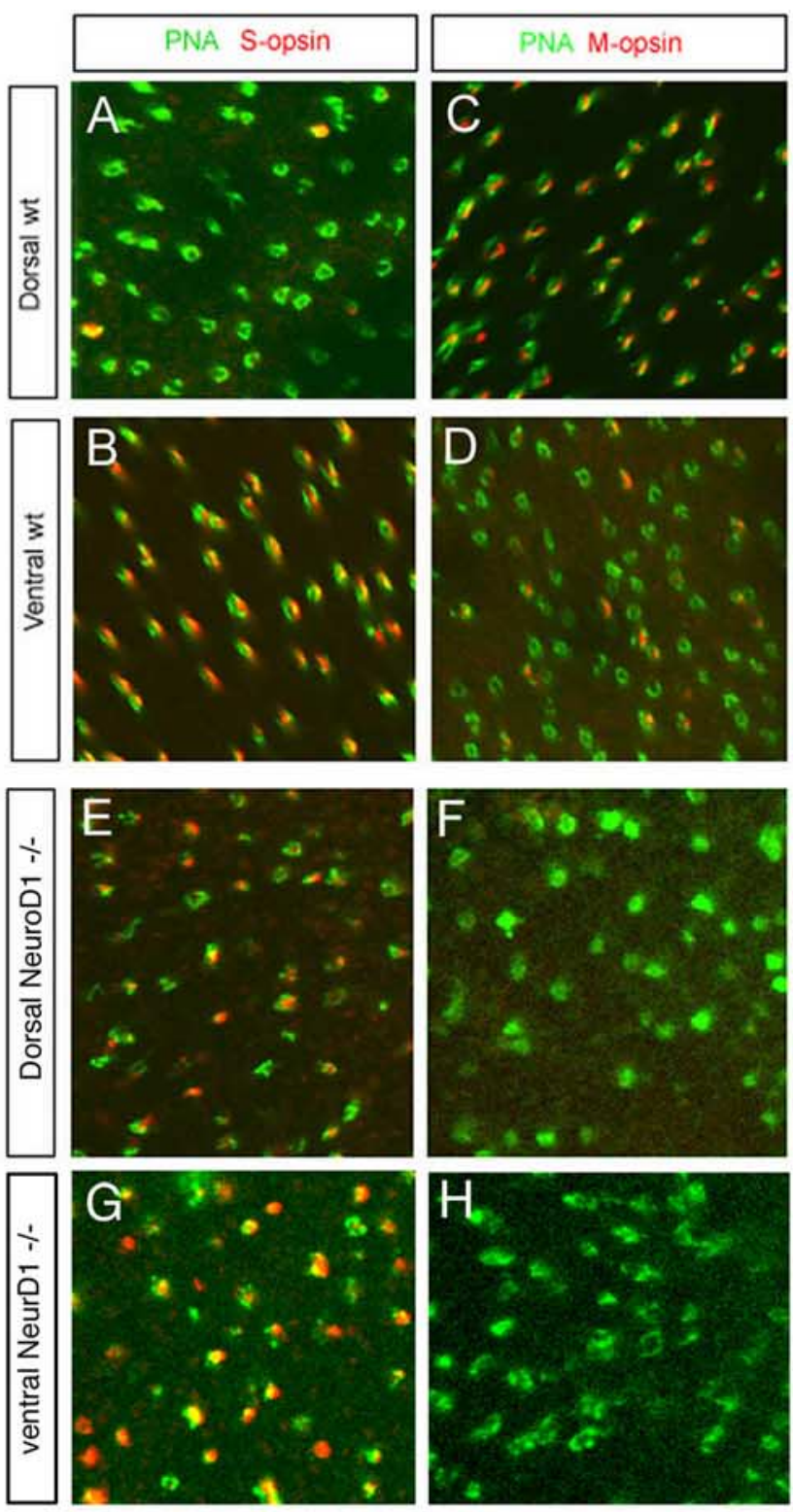

I

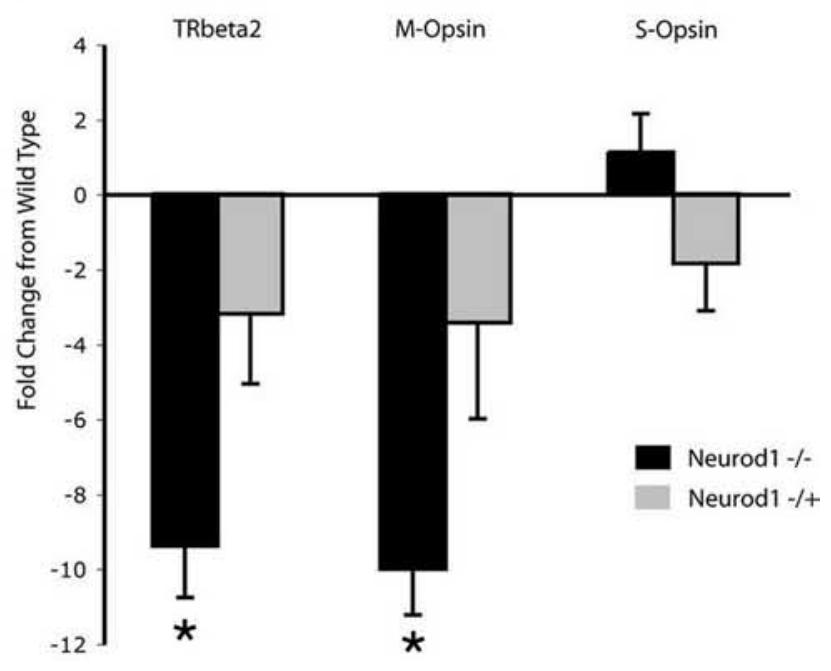

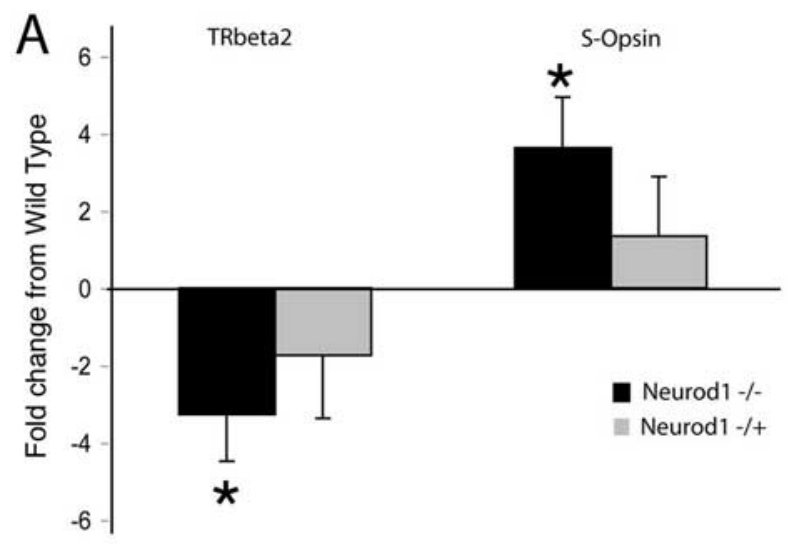

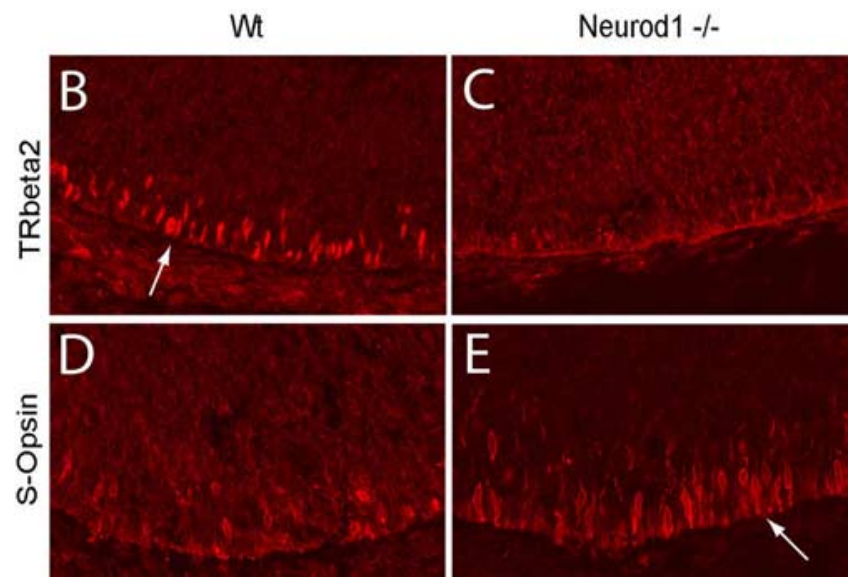

Figure 3. NeuroD1 regulates TR $\beta 2$ expression in embryonic retina. $A$, Quantitative PCR at E18 shows a significant reduction in TR $\beta 2$ and a corresponding increase in S-opsin mRNA. Error bars indicate SD. ${ }^{*} p<0.01$. $\boldsymbol{B}-\boldsymbol{E}$, TR $\beta 2$ immunolabeling in wild-type $(\boldsymbol{B})$ and NeuroD1 ${ }^{-1-}$ retina $(\boldsymbol{C})$, showing the large reduction in TR $\beta 2$ expression. $\boldsymbol{D}, \boldsymbol{E}$, $\boldsymbol{S}$-opsin is prematurely expressed in the NeuroD1 ${ }^{-1-}$ mouse retinas. Few cells are labeled in $\boldsymbol{D}$, because E18 represents the onset of S-opsin expression, but in the mutant retinas there is robust $\mathrm{S}$-opsin expression.

roD1 ${ }^{-1-}$ mouse retina at E17. In wild-type embryos, there are only a few scattered S-opsin-expressing cones, whereas there is robust S-opsin labeling in the NeuroD1 ${ }^{-1-}$ retinas (Fig. $3 D, E$ ).

To test whether replacing NeuroD1 in the retina of NeuroD $1^{-1-}$ mice would restore TR $\beta 2$ expression, we used electroporation to transfect retinas of E14 NeuroD1 ${ }^{-1-}$ and NeuroD $1^{+/-}$mice, and then cultured the retinas as explants for $4 \mathrm{~d}$ before immunolabeling for TR $\beta 2$ (Fig. 4). In previous studies, we found that our conditions primarily transfect progenitor cells (Nelson et al., 2006); however, after $4 \mathrm{~d}$ of culture, many of the cells developed into both ganglion cells and cones, consistent with the cells types produced at these early stages of retinal development. We found that those regions of the NeuroD1 ${ }^{-1-}$ retinas

\section{$\leftarrow$}

Figure 2. Flat mounts of wild-type $(\boldsymbol{A}-\boldsymbol{D})$ and NeuroD1-deficient $(\boldsymbol{E}-\boldsymbol{H})$ postnatal day 14 mouse retinas labeled for either S-opsin or M-opsin (red) and with PNA (green), to label the total cone population, show the loss of M-opsin expression. Wild-type animals $(\boldsymbol{A}-\boldsymbol{D})$ have a distinct gradient in cone expression, with M-opsin predominant in the dorsal retina and $\mathrm{S}$-opsin-expressing cones present at greater relative numbers in the ventral retina. Neu$\mathrm{roD}^{-/-}$retinas $(\boldsymbol{E}-\boldsymbol{H})$ have only S-opsin-expressing cones; there is little to no M-opsin expression. I, Quantified real-time PCR shows a $\sim 10$-fold reduction in the expression of M-opsin and TR $\beta 2$ in retinas of NeuroD1 ${ }^{-/-}$mice compared with wt mice at postnatal day 12 . S-opsin RNA expression is not significantly changed in NeuroD1 ${ }^{+/-}$or NeuroD1 ${ }^{-/-}$mice. Error bars indicate SD. ${ }^{*} p<0.01$. 


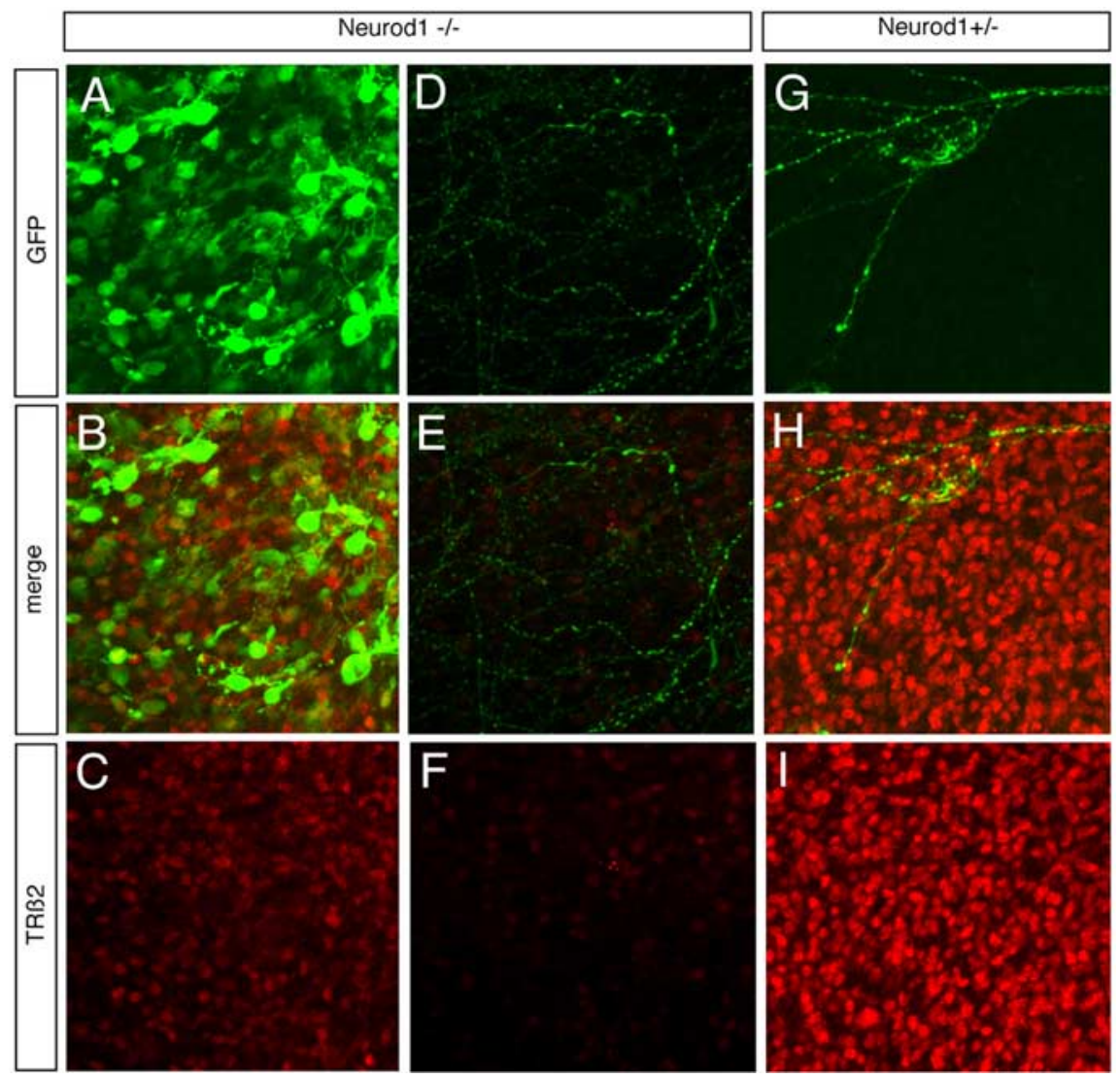

Figure 4. NeuroD1 stimulates TR $\beta 2$ expression in embryonic retina. Retinas from E14 NeuroD1 ${ }^{-/-}$and NeuroD1 ${ }^{+/-}$mice were cotransfected with plasmids expressing NeuroD1, E12, and GFP by electroporation. After culture as explants for $4 \mathrm{~d}$, the retinas were fixed and labeled for TR $\beta 2$ (red) and imaged by confocal microscopy. GFP (green) indicates the region of transfection, in $\boldsymbol{A}-\boldsymbol{C}$, whereas $\boldsymbol{D}$ and $\boldsymbol{E}$ show a nontransfected region from the same retina. TR $\beta 2+$ cells are abundant in the transfected region $(\boldsymbol{A}-\boldsymbol{C})$, but not in the untransfected region $(\boldsymbol{D}-\boldsymbol{F})$. Note, the green fibers in $\boldsymbol{D}, \boldsymbol{E}, \boldsymbol{G}$, and $\boldsymbol{H}$ are from cells that developed into ganglion cells in the $4 \mathrm{~d}$ of culture and have sent axons across the retina. $\mathbf{G}-\mathbf{I}$ show the level of TR $\beta 2$ expression in a nontransfected region of a GFP transfected NeuroD1 ${ }^{+/-}$embryo sister cultured retina, from the same litter for comparison. Although forced expression of NeuroD1 in NeuroD1 ${ }^{-1-}$ retina upregulates $\operatorname{TR} \beta 2$ ( C VS $\left.\boldsymbol{F}\right)$, it does not restore it to normal levels.

bHLH transcription factors at position 600 (E600) (CAGGTG) (Fig. 5B).

The role of NeuroD1 in activating through the intron control region was tested by cotransfection assays in Weri retinoblastoma cells, which are permissive for endogenous TR $\beta 2$ expression and which express several cone markers (Li et al., 2003) as well as NeuroD1 (Fig. 6A). $\mathrm{TR} \beta 2$ has highly restricted expression in vivo and it is found in only a few cell lines in culture (Jones et al., 2007). In Weri cells, the intron conferred a fourfold increase in luciferase activity compared with the promoter alone when incorporated in the episomal reporter vector pREP4 (Fig. 5C,D). The induction was observed only in this chromatin-forming reporter vector and not in a non-chromatin-forming vector (Jones et al., 2007). Cotransfection of a vector that overexpresses NeuroD1 superinduced luciferase levels, up to twofold, in an intron-dependent manner. In 293T cells, which do not express NeuroD1, neither the intron nor transfected NeuroD1 induced luciferase activity, consistent with the need for additional cell-specific factors for the response. The intron-mediated induction of the TR $\beta 2$ promoter in Weri cells was reduced by expression of si-RNA against endogenous NeuroD1 (Fig. 5E) (Liu et al., 2001). The partial inhibition is consistent with NeuroD1 being one factor of a complex that mediates the full induction of TR $\beta 2$ in cones, as indicated by the transgenic mapping of the cone-specific control region in vivo (Jones et al., 2007). Detailed deletion mapping in Weri cells located the major NeuroD1-responsive re-

that were transfected with NeuroD1 and E12 (a dimerizing partner for bHLH transcription factors) showed expression of TR $\beta 2$ (Fig. $4 A-C$ ), whereas those areas of the same retinas without transfection did not (Fig. $4 D-F$ ). There was not a perfect correlation between the cells that were labeled for GFP and those that expressed TR $\beta 2$, but this is likely attributable to the fact that the cotransfection efficiency for all three plasmids is not $100 \%$. Retinas from NeuroD $1^{+/-}$embryos cultured from the same litter were used as a positive control (Fig. $4 G-I$ ). Note, the green fibers in Figure $4, D, E, G$, and $H$, are from cells that developed into ganglion cells in the $4 \mathrm{~d}$ of culture, and have sent axons across the retina.

The phenotype of the NeuroD $1^{-/-}$mice suggests that NeuroD1 is necessary for the maintenance of TR $\beta 2$ expression during cone photoreceptor development. The genomic sequences of the Thrb gene that direct cone-specific induction of TR $\beta 2$ were recently mapped in mice using reporter transgenes carrying the natural TR $\beta 2$ promoter (Jones et al., 2007). An intron control region located $2 \mathrm{~kb}$ downstream from the TR $\beta 2$ first coding exon was necessary for both pituitary and cone-specific expression (Fig. 5A). The complex 300 bp domain for cone-specific expression contained "specifier" and "amplifier" elements that together give full expression in the immature cone population. The "amplifier" domain includes a conserved E-box binding site for gion between positions 580 and 660 of the intron fragment, which encompassed the E600 site (Fig. $5 F$ ). Mutation of the E600 site in the context of the full-length $730 \mathrm{bp}$ fragment $(+730$ M600) severely reduced the inducibility by NeuroD1.

NeuroD1 present endogenously in Weri cell extracts was shown to bind directly to the E600 site by electrophoretic mobility shift assay (Fig. 6A,B). Nuclear extracts of Weri but not 293T cells gave a shifted band with a 20 bp probe containing the E600 site. The specificity of the band was indicated by efficient competition with a wild-type probe but not with a mutant probe. The band was also sensitive to abolition by antibody against NeuroD1 but not by irrelevant antisera. 293T cells transfected with a NeuroD1 expression vector gave a similar band as that given by Weri cells. Weri nuclear extracts also gave a specific band with a control probe, a known binding site for NeuroD1 in the secretin gene (Mutoh et al., 1997) (data not shown). Analysis of Weri cells by ChIP followed by quantitation by RT-PCR detected enriched binding of endogenous NeuroD1 in the cone-specific domain of the intron control region of the Thrb gene (Fig. $6 C, D$ ). Little or no specific binding was detected at more distal genomic sequences and no specific binding was detected in this intron in $293 \mathrm{~T}$ cells. ChIP analysis of embryonic mouse retina supported the proposal that NeuroD1 binds the intron control region in vivo (data not shown). 
A

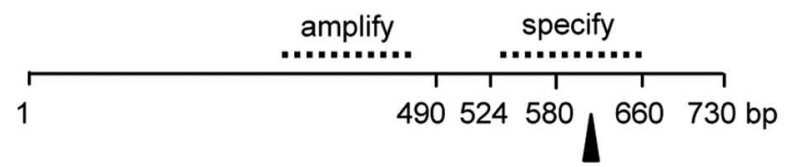

Wild type E-box ACACAGGTGTTC Mutant M600 ACAGCTAGCTTC

B

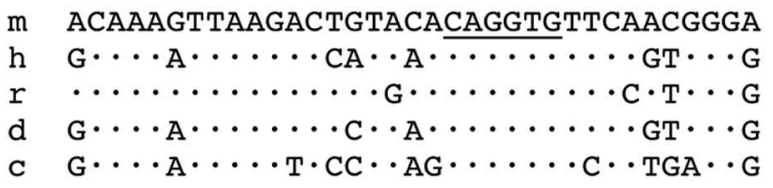

C
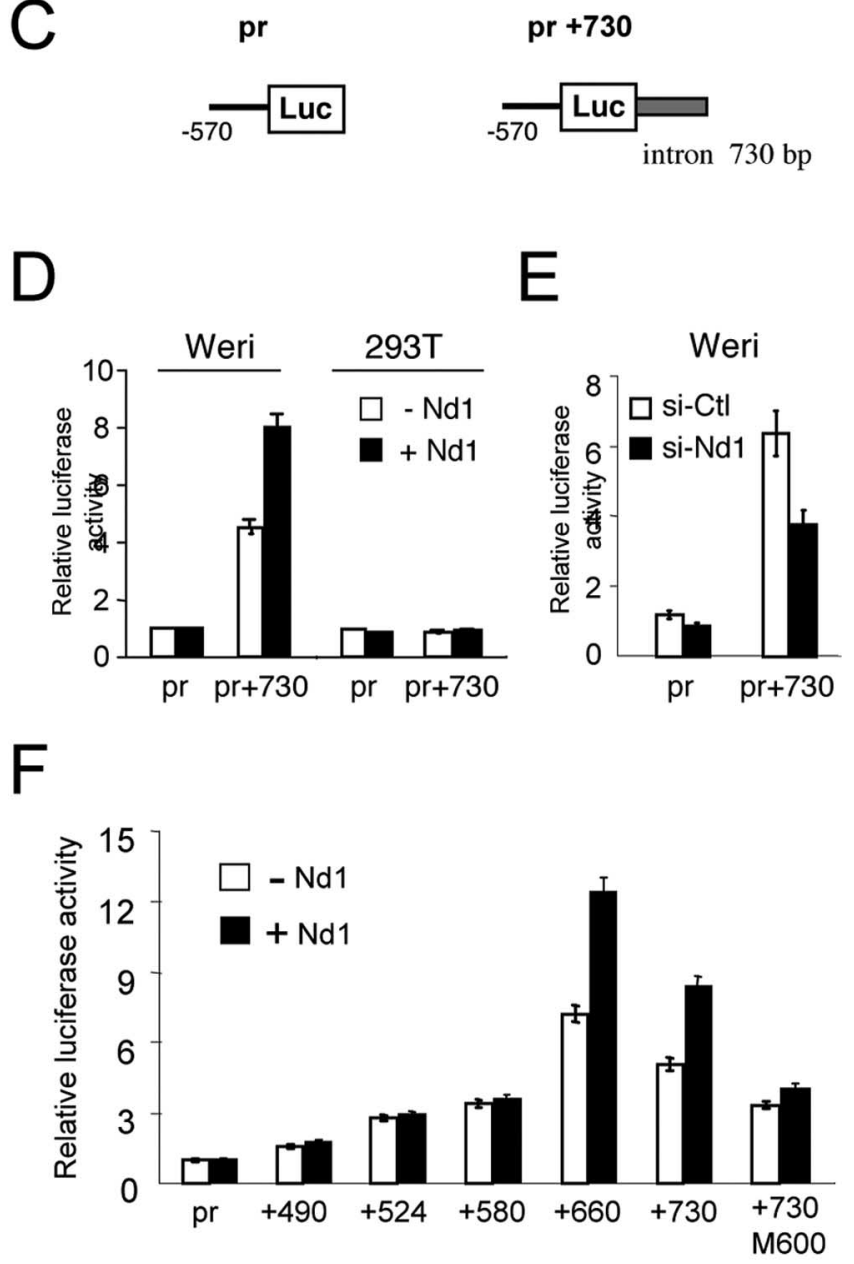

pr + intron fragment

Figure 5. The Thrb intron control region mediates NeuroD1-dependent activation of the TR $\beta 2$ promoter. $\boldsymbol{A}$, The cone-specific control region shown within a $730 \mathrm{bp}$ intron fragment of the Thrb gene. The E-box resides at base position 600 . The $\mathrm{M} 600$ mutation used in $\boldsymbol{F}$, has all six bases changed. $\boldsymbol{B}$, The E-box is conserved in several species; the sequences shown begin at the given base coordinates downstream of the TR $\beta 2$ coding exon: mouse, $m(1940)$; human, $h$ (1953); rat, r (1935); dog, d (2017); chick, c (2018). C, pREP4 luciferase reporters carrying the TR $\beta 2$ promoter without ( $p r)$ or with the 730 bp intron fragment $(\mathrm{pr}+730)$. $\boldsymbol{D}$, Intron-mediated luciferase induction in Weri but not 293T cells; + / - Nd1, with or without cotransfected pSG5NeuroD1. Luciferase activity is relative to the level "1" assigned to the promoter construct alone.

\section{Discussion}

The present study shows that NeuroD1 plays an important role in cone opsin patterning in development and that it is necessary for correct expression of TR $\beta 2$, a key factor in determining the patterning of opsins. Our previous work has shown that TR $\beta 2$ is required for the repression of S-opsin and the induction of $\mathrm{M}$-opsin in subsets of cone photoreceptors. The opsin phenotype of NeuroD1 $1^{-1-}$ mice is remarkably similar to that of the $\mathrm{TR} \beta 2^{-1-}$ mice. The evidence is consistent with NeuroD1 playing a direct role in TR $\beta 2$ expression, because the cone-specific element of the Thrb gene contains an E-box that is bound and activated by NeuroD1, and mutation of this site results in loss of activation. These results provide the first evidence for a direct target of NeuroD1 in the mammalian retina.

The programming of opsin expression in cones appears to occur soon after these cells have withdrawn from the cell cycle. Although previous studies of NeuroD1 in the retina have shown that the gene is expressed in developing and mature photoreceptors (Kanekar et al., 1997; Ahmad et al., 1998; Yan and Wang, 1998, 2004; Morrow et al., 1999), double-labeling for NeuroD1 expression and BrdU shows that the majority of the NeuroD1expressing cells are postmitotic. This is consistent with our previous findings that $\operatorname{TR} \beta 2$ and its heterodimeric partner, $\operatorname{RXR} \gamma$, are also expressed in newly postmitotic cone photoreceptors $(\mathrm{Ng}$ et al., 2001; Roberts et al., 2005, 2006; Jones et al., 2007).

Previous studies have used both gain- and loss-of-function approaches to determine the role of NeuroD1 in the retina. The gain-of-function approaches have led to a variety of conclusions, depending on the species, and timing of expression. For example, when NeuroD1 is overexpressed in chick embryo retina, there is an increase in the number of visinin- and Map2-labeled cells and an increase in the ONL thickness (Yan and Wang, 1998). Thus, Yan and Wang (2000) proposed that NeuroD1 is a "prophotoreceptor gene." Interestingly, they also analyzed opsin gene expression in the cells overexpressing NeuroD1 and found a large overrepresentation in red opsin expression, the opsin in birds closest to the M-opsin of mice. Overexpression of NeuroD1 in retinal progenitors in rat and mouse explant cultures (Ahmad et al., 1998; Morrow et al., 1999; Inoue et al., 2002) gave varying results on bipolar cells, Müller glia and amacrine cells, but all reports showed some increase in the percentages of photoreceptors in the cultures. Although none of these previous studies analyzed expression of TR $\beta 2$ after overexpression, our data show that overexpression of NeuroD1 in the retina of NeuroD $1^{-1-}$ mice leads to rescue of TR $\beta 2$ expression.

Previous loss-of-function analyses have also implicated NeuroD1 in photoreceptor development and/or survival. Morrow et al. (1999) reported an increase in apoptotic cells in the ONL of the NeuroD $1^{-l-}$ explant retinas over that observed in wild-type retinas after 12 d in vitro. A $20 \%$ reduction in the ONL cell number in NeuroD $1^{-1-}$ mouse retinal explants was observed by Inoue et al. (2002), and Pennesi et al. (2003) reported a 20-30\% reduction in ONL cell number in vivo. This was attributable to photorecep-

$\leftarrow$

E, Transfection of vectors expressing a mix of interfering RNA (si-Nd1) against endogenous NeuroD1 reduced the intron-mediated induction of luciferase. A control vector (si-ctl) did not inhibit activity. $\boldsymbol{F}$, Mapping the NeuroD1-responsive site in the intron in transfected Weri cells. The reporter construct carried the TR $\beta 2$ promoter (pr) in conjunction with varying lengths of intron sequence (in base pairs) downstream of luciferase, as indicated below the horizontal axis. The construct " $+730 \mathrm{M} 600$ " carries the M600 mutation of the E-box in the context of the $730 \mathrm{bp}$ intron fragment. Error bars indicate SEM. 
A

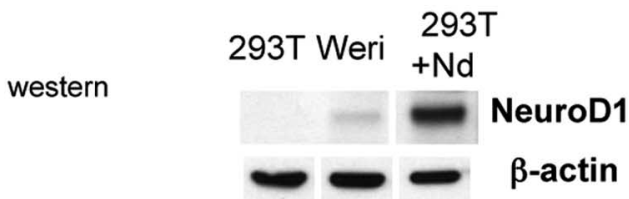

B
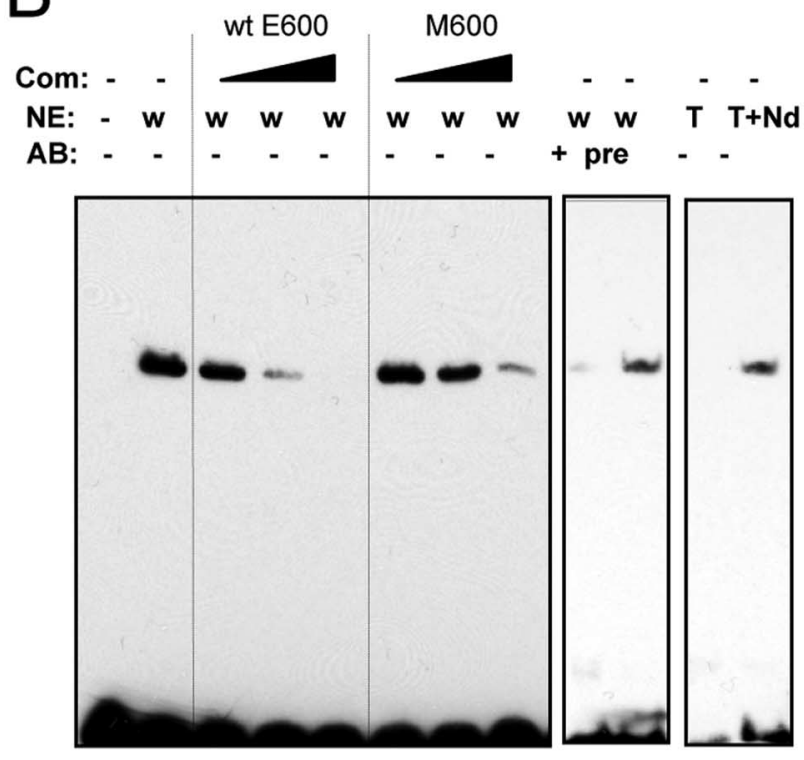

EMSA Probe: wild type E600

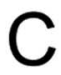

ChIP probe:

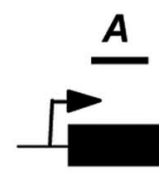

TRß2 exon

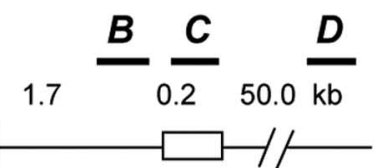

intron control region
IgG anti

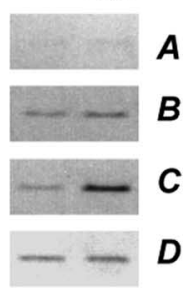

$\boldsymbol{A}$

$B$

$C$

$D$
D

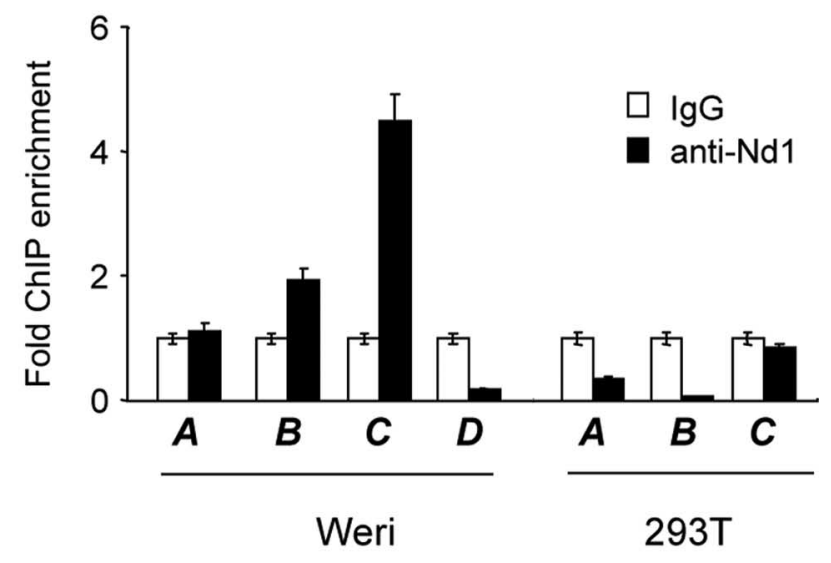

ChIP probe tor degeneration, rather than specific inhibition in their development. Similar results have been obtained in embryonic chick retina. Yan and Wang (2004) used antisense RNA and RNA interference to knock-down NeuroD1 in embryonic chick retina, as well as a NeuroD1-engrailed repressor construct. These treatments caused reductions in the photoreceptors (visinin + cells) and defects in the outer nuclear layer, consistent with photoreceptor degeneration.

The degeneration of rod and cone photoreceptors that occurs in NeuroD $1^{-1-}$ mice is likely separable from the effects we observe on TR $\beta 2$, because TR $\beta 2^{-\prime-}$ mice do not have degeneration in either rod or cone photoreceptors (Ng et al., 2001). Although the rod degeneration in NeuroD1 $1^{-/-}$mice begins before birth (Pennesi et al., 2003), the cone photoreceptors do not show the same degree of degeneration. We did not find a significant difference in the number of cones by postnatal day 12 . This suggests that, although NeuroD1 is important in the regulation of opsin expression in cones, it is not as critical for cone generation or survival. It is interesting that TR $\beta 2$, RXR $\gamma$, and NeuroD1, transcription factors that are known to have specific functions in the cone pathway, do not control the commitment to a cone fate but instead act in the postmitotic cone to program opsin patterning.

As noted above, mice have a distinct gradient in opsin expression, with a greater percentage of $\mathrm{M}$-opsin-expressing cones in the dorsal retina and a greater percentage of S-opsin cones in the ventral retina. Our previous work has shown that the formation of this gradient during development requires $\operatorname{TR} \beta 2, \operatorname{RXR} \gamma$, and a gradient of thyroid hormone ( $\mathrm{Ng}$ et al., 2001; Roberts et al., 2005, 2006). Although TR $\beta 2$ and RXR $\gamma$ are initially expressed in apparently all cones, they are downregulated around birth in complex patterns (Roberts et al., 2005, 2006; Jones et al., 2007); however, we have not detected a gradient in expression of either of these transcription factors at any point in development that would correspond to the gradients in opsin expression. Consistent with this finding, we did not detect a gradient in NeuroD1 expression at any stage of development. Rather, it appears that a gradient in the ligand for TR $\beta 2$, thyroid hormone, contributes to the dorsal-ventral gradient in M-opsin expression (Roberts et al., 2006). However, there does not appear to be a graded concentration of thyroid hormone at the age when the S-opsin expression pattern is established, and so the mechanism that sets up this pattern remains to be identified.

The patterning of cone opsins reflects the interplay of several mechanisms that are initiated in the newly generated cone. TR $\beta 2$ acts as a switch between S- and M-opsin identities and the expres-

$\leftarrow$

Figure 6. NeuroD1 binds to the intronic E-box (E600). $A$, Weri cells express modest amounts of endogenous NeuroD1, detected by Western blot. 293T cells lack detectable NeuroD1 but transfection of pSG5-NeuroD1 produces a NeuroD1 band similar to that in Weri cells. B, EMSA showing that NeuroD1 in nuclear extracts (NE) of Weri cells $(w)$ binds to a wt probe containing E600. Competition with increasing amounts of unlabeled wt probe (com) abolishes the band $(10-, 100-, 1000$-fold excesses), whereas a mutant form of the probe (M600) competes weakly. Antibody (AB) against NeuroD1 but not irrelevant antisera (preimmune, pre) reduced the specific band. Control 293T cells transfected with pSG5-NeuroD1 $(T+N d)$ gave a similar band on EMSA as did endogenous NeuroD1 in Weri cells. $C$, Detection by ChIP of NeuroD1 bound to the intron control region. Location of ChIP probes $(A, B, C, D)$ is shown above a diagram of the relevant part of the human THRB gene. The right panel shows an example of PCR products, visualized on an ethidium bromide-stained gel, generated for each probe in Weri cells on use of Ig G control or anti-NeuroD1 serum. D, Quantitation of ChIP products obtained from Weri or 293T cells was performed by RT-PCR. NeuroD1 was enriched in the region of probe $C$, but not in more distal regions of the THRB gene in Weri cells. 293T cells, which do not express TR $\beta 2$, showed no enrichment of bound NeuroD1. Error bars indicate SEM. 
sion of TR $\beta 2$ is at least partly under the control of NeuroD1. However, NeuroD1 alone cannot induce TR $\beta 2$ expression in nonpermissive cell types in transfection assays, suggesting a requirement for cooperation with other cell-specific factors. Indeed, in NeuroD1 $1^{-1-}$ mice, TR $\beta 2$ is initially induced, at least partially, but fails to be sustained, in accord with the proposal that NeuroD1 is one component of a complex that mediates the appropriate expression pattern of the Thrb gene. Such cooperation is consistent with the requirement for regulatory sequences that extend beyond the E-box in the control region of the Thrb gene for the full induction of TR $\beta 2$ in cones in vivo (Jones et al., 2007). The future identification of such cooperating factors may suggest new genes that control cone opsin identity.

\section{References}

Ahmad I, Acharya HR, Rogers JA, Shibata A, Smithgall TE, Dooley CM (1998) The role of NeuroD as a differentiation factor in the mammalian retina. J Mol Neurosci 11:165-178.

Furukawa T, Morrow EM, Cepko CL (1997) Crx, a novel otx-like homeobox gene, shows photoreceptor-specific expression and regulates photoreceptor differentiation. Cell 91:531-541.

Inoue T, Hojo M, Bessho Y, Tano Y, Lee JE, Kageyama R (2002) Math3 and NeuroD regulate amacrine cell fate specification in the retina. Development 129:831-842.

Jones I, Ng L, Liu H, Forrest D (2007) An intron control region differentially regulates expression of thyroid hormone receptor $\beta 2$ in the cochlea, pituitary and cone photoreceptors. Mol Endocrinol 21:1108-1119.

Kanekar S, Perron M, Dorsky R, Harris WA, Jan LY, Jan YN, Vetter ML (1997) Xath5 participates in a network of bHLH genes in the developing Xenopus retina. Neuron 19:981-994.

Kubota R, McGuire C, Dierks B, Reh TA (2004) Identification of ciliary epithelial-specific genes using subtractive libraries and cDNA arrays in the avian eye. Dev Dyn 229:529-540.

Lee JK, Cho JH, Hwang WS, Lee YD, Reu DS, Suh-Kim H (2000) Expression of neuroD/BETA2 in mitotic and postmitotic neuronal cells during the development of nervous system. Dev Dyn 217:361-367.

Li A, Zhu X, Brown B, Craft CM (2003) Gene expression networks underlying retinoic acid-induced differentiation of human retinoblastoma cells. Invest Ophthalmol Vis Sci 44:996-1007.

Liu M, Pleasure SJ, Collins AE, Noebels JL, Naya FJ, Tsai MJ, Lowenstein DH (2000a) Loss of BETA2/NeuroD leads to malformation of the dentate gyrus and epilepsy. Proc Natl Acad Sci USA 97:865-870.

Liu M, Pereira FA, Price SD, Chu MJ, Shope C, Himes D, Eatock RA, Brownell WE, Lysakowski A, Tsai MJ (2000b) Essential role of BETA2/NeuroD1 in development of the vestibular and auditory systems. Genes Dev 14:2839-2854.
Liu R, Liu H, Chen X, Kirby M, Brown PO, Zhao K (2001) Regulation of CSF1 promoter by the SWI/SNF-like BAF complex. Cell 106:309-318.

Morrow EM, Furukawa T, Lee JE, Cepko CL (1999) NeuroD regulates multiple functions in the developing neural retina in rodent. Development 126:23-36.

Mutoh H, Fung BP, Naya FJ, Tsai MJ, Nishitani J, Leiter AB (1997) The basic helix-loop-helix transcription factor BETA2/NeuroD is expressed in mammalian enteroendocrine cells and activates secretin gene expression. Proc Natl Acad Sci USA 94:3560-3564.

Nelson BR, Gumuscu B, Hartman BH, Reh TA (2006) Notch activity is downregulated just prior to retinal ganglion cell differentiation. Dev Neurosci 28:128-141.

Nelson BR, Hartman BH, Georgi SA, Lan MS, Reh TA (2007) Transient inactivation of Notch signaling synchronizes differentiation of neural progenitor cells. Dev Biol 304:479-498.

Ng L, Hurley JB, Dierks B, Srinivas M, Salto C, Vennstrom B, Reh TA, Forrest D (2001) A thyroid hormone receptor that is required for the development of green cone photoreceptors. Nat Genet 27:94-98.

Nishida A, Furukawa A, Koike C, Tano Y, Aizawa S, Matsuo I, Furukawa T (2003) Otx2 homeobox gene controls retinal photoreceptor cell fate and pineal gland development. Nat Neurosci 6:1255-1263.

Pennesi ME, Cho JH, Yang Z, Wu SH, Zhang J, Wu SM, Tsai MJ (2003) BETA2/NeuroD1 null mice: a new model for transcription factordependent photoreceptor degeneration. J Neurosci 23:453-461.

Roberts MR, Hendrickson A, McGuire CR, Reh TA (2005) Retinoid X receptor (gamma) is necessary to establish the S-opsin gradient in cone photoreceptors of the developing mouse retina. Invest Ophthalmol Vis Sci 46:2897-2904.

Roberts MR, Srinivas M, Forrest D, Morreale de Escobar G, Reh TA (2006) Making the gradient: thyroid hormone regulates cone opsin expression in the developing mouse retina. Proc Natl Acad Sci USA 103:6218-6223.

Srinivas M, Ng L, Liu H, Jia L, Forrest D (2006) Activation of the blue opsin gene in cone photoreceptor development by retinoid-related orphan receptor $\beta$. Mol Endocrinol 20:1728-1741.

Weinmann AS, Bartley SM, Zhang T, Zhang MQ, Farnham PJ (2001) Use of chromatin immunoprecipitation to clone novel E2F target promoters. Mol Cell Biol 20:6820-6832.

Yan RT, Wang SZ (1998) neuroD induces photoreceptor cell overproduction in vivo and de novo generation in vitro. J Neurobiol 36:485-496.

Yan RT, Wang SZ (2000) Expression of an array of photoreceptor genes in chick embryonic retinal pigment epithelium cell cultures under the induction of neuroD. Neurosci Lett 280:83-86.

Yan RT, Wang SZ (2004) Requirement of neuroD for photoreceptor formation in the chick retina. Invest Ophthalmol Vis Sci 45:48-58.

Zhang J, Gray J, Wu L, Leone G, Rowan S, Cepko CL, Zhu X, Craft CM, Dyer MA (2004) Rb regulates proliferation and rod photoreceptor development in the mouse retina. Nat Genet 36:351-360. 